\title{
Da geração 2000 à geração Meia-noite e vinte: o realismo engenhoso de Daniel Galera
}

\author{
David Lopes da Silva* \\ "A trilha tinha terminado num abismo. \\ Saí apressado em direção ao Bom Fim, \\ sem rumo definido". \\ (Galera: 2016, 189)
}

No pequeno ensaio "Minha cegueira”, publicado em 2005, Bernardo Carvalho identifica uma disposição recorrente, "uma tendência cíclica na literatura brasileira, e que hoje me parece estar se tornando de novo um paradigma. No Brasil, é comum tratar a literatura como documento histórico ou sociológico. E privilegiar a literatura que mais se presta a isso". Para o autor de Nove noites, tal propensão denunciaria uma espécie de "naturalismo", que não percebe ou finge ignorar que "tudo em literatura é criação, do aparente documento à ficção mais inverossímil" - e essa propensão seria própria não apenas dos escritores que supostamente trazem para o texto a "voz das ruas", mas o "mais curioso é que esse naturalismo também norteia autores das novas gerações que procuram falar de si com maior veracidade".

Pretendemos, neste ensaio, evidenciar como - afora a indiscutível notoriedade com que Daniel Galera tem garantido o efeito de

\footnotetext{
* Professor adjunto da Universidade Federal de Alagoas (UFAL), campus Arapiraca.
} 
real de sua ficção (cf. Assis: 2014, 131, que cita inclusive entrevista em que o próprio autor afirma que "buscou em seu romance [Barba ensopada de sangue] um registro o mais próximo possível do realismo descritivo") - seu romance Meia-noite e vinte exibe com muita habilidade as marcas de sua construção, a partir de pequenas trucagens que, se resultam na coesão do conjunto do livro, ao mostrarem-se também como artifícios deliberados que conectam, por exemplo, partes determinadas do enredo, chamam sobre si a atenção do leitor, solapando a ilusão de um realismo simplório, peculiar ao grupo de escritores possivelmente visado pela crítica de Carvalho: o texto de Galera vai além da mera tendência a "ocultar o objeto imitante em proveito do objeto imitado" (Compagnon: 2003, 106) e, ao invés de "mascara[r] seus próprios processos de ficcionalização" (Jaguaribe: 2007, 15), deixa-os ali, nas entrelinhas, pedindo uma releitura atenciosa. ${ }^{1}$

Sendo assim, em que pese o "realismo exacerbado" que Beatriz Resende encontra em Mãos de cavalo (2008), e, mesmo que tal romance tenha sido aproximado "da visão cientificista do naturalismo" por Cristhiano Aguiar, que defende inclusive que, nele, "[o] ato criador de Galera propositadamente procura apagar as marcas de ficcionalidade do texto" (Aguiar: 2010, 74), tentaremos sublinhar essas marcas de ficcionalidade em Meia-noite e vinte, realçando o "sofisticado trabalho com a linguagem literária" (Cunha: 2011, 452-3), assim como sua “sofisticada estrutura narrativa” (Cunha: 2011, 452-3).

Nesse sentido, no primeiro momento apenas seguiremos a trilha aberta por Cunha, que em Cordilheira detecta uma

\footnotetext{
${ }^{1}$ Tal conceito raso de "realismo" é criticado tanto por Compagnon quanto por Jaguaribe, mas esperamos que mesmo assim sirva ao propósito inicial de mostrar a engenhosidade da composição de Galera, a fim de ensaiarmos as duas hipóteses interpretativas.
} 
invenção formal que articula segmentos narrativos aparentemente desconectados, [mas] que, no entanto, já fora testada, com eficácia, como vimos nos dois romances anteriores [Mãos de cavalo e Até o dia em que o cão morreu], e pode ser vista, assim, como princípio constituinte do estilo em Galera (2011, 456; grifo nosso).

\section{Primeiras conexões}

Em Meia-noite e vinte, os elementos da cultura pop abundam, mas parecem contidos e medidos: longínquos da Máquina de pinball de 2002, que trazia, no fim, a nota afrontosa mandando o leitor ("amigão") que se virasse, devido às "muitas expressões e frases em inglês da série 'letras não traduzidas”" (Averbuck: 2002, 78). Meianoite e vinte está cravejado de expressões em inglês, que, entretanto, agora não recebem mais nem o itálico: o leitor não precisa se virar mais. É assim que, apesar de entremeado de referências à tecnologia dos anos 1990, o livro não resvala para o saudosismo, ${ }^{2}$ graças à quantidade bem maior de expressões oriundas da web atual, as quais desempenham, inclusive, papel central em diversos momentos da narrativa, deixando os Atari e Odyssey apenas como esboço de projeto arqueológico, mesmo que algumas madeleines tenham sabor amargo, por tão próximas e já tão distantes (por outro lado, restará por construir a ponte entre a Enciclopédia de criptozoologia de Aurora e a "arqueologia da zoologia" da Gradiva de Freud).

2 Em seu lançamento no segundo semestre de 2016, a exemplo do que se lê na matéria de Silvio Essinger em $O$ Globo de 17/9/2016, a recepção inicial do romance por parte dos cadernos culturais da grande mídia, a nosso ver, repercutiu diversos erros de leitura: "Meia-noite e vinte serve como um mote para Daniel Galera olhar para trás e, sim, ceder um pouco ao saudosismo". 
O telefone celular conectado às redes sociais, por exemplo, atravessa toda a estória, da primeira página ao penúltimo capítulo, funcionando como gancho especialmente nas aberturas e fechamentos dos dois primeiros capítulos, e até mesmo no bucólico capítulo final, no qual tampouco deixa de comparecer. No entanto, gostaríamos de afastar uma aparente semelhança com A vez de morrer, de Simone Campos, cujo cenário rupestre, embora também seja procurado pela personagem devido a uma crise com a vida metropolitana, tem lan house e é onde se passa a maior parte das ações: mais pertinente talvez seja a aproximação do romance de Campos a Barba ensopada de sangue (cf. Brito: 2014).

Mas, adentrando de vez o romance de que tratamos aqui, parte de sua recepção de primeira hora não registrou um detalhe importante de seu enredo: o "momento da narração" - o qual "remete ao momento em que a história é contada, em relação ao momento em que supostamente ela se desenrola" (Reuter: 2002, 88) -, por isso foi quase unânime a acusação de se tratar de livro apocalíptico, niilista, desesperançado.

Entretanto, o próprio Galera, em entrevista concedida a Camila Von Holdefer em 2016, chamaria a atenção para o desejo de

infiltrar no leitor a sensação de que essas vozes narram de um futuro distante em que tudo mudou [...]. Nossa época, no livro, é na verdade uma lembrança distante. Existe uma vibração de fundo no romance, algo não narrado, que sugere a superação dos impasses.

Não narrado mas indicado, e com clareza: os trechos que não foram notados e acabaram por enviesar algumas leituras para 
o suposto lado do pessimismo estão estrategicamente dispostos no primeiro parágrafo do livro e no início do último capítulo, ambos narrados por Aurora:

Desespero geral pela onda de calor que esmagava Porto Alegre naquele final de janeiro, mas, se houve um antes e um depois, um marco entre a vida que parecia que eu iria ter e a vida que tive, esse marco foi a notícia de que o Andrei havia sido assassinado num assalto à mão armada, na noite anterior (2016, 7; grifos nossos).

Hoje sabemos bem o que nos aguardava, mas eu estava no escuro como todo mundo quando despertei naquela manhã [no sítio dos pais de Emiliano, inverno de 2014], aos primeiros indícios da alvorada (2016, 197; grifos nossos). ${ }^{3}$

Ou seja: a narração de Meia-noite e vinte de forma alguma é "simultânea" (Reuter: 2002, 88), isto é, ocorre em período bem posterior aos fatos do primeiro semestre de 2014, posterior mesmo ao inverno desse ano.

Como essas, há muitas sutilezas da escrita que demandam a atenção do leitor para o caráter artificioso do romance: o travesti que interage com Aurora logo no começo do livro (trazendo a consideração da temática de gênero desde o princípio), por exemplo, retorna perto do final, quando é Emiliano que agora está sentado na calçada,

\footnotetext{
${ }^{3}$ Além dessas duas passagens-chave, há pelo menos mais uma, também de Aurora, na página 15: "Na manhã em que fiquei sabendo [do assassinato do Andrei] [...]".
} 
depois da meia-noite, chocado com o que acabara de descobrir sobre Andrei; já a sugestão de Emiliano para que Aurora sentasse na cara do professor César repete as cenas do filme de Duque e Antero; e Antero, no final do excurso de dez páginas sobre o Marquês de Sade, ${ }^{4}$ cuja narrativa algorítmica "é um procedimento semelhante a uma análise combinatória" (o "procedimento sádico"), explica, na sequência, as ideias de Giane sobre a narrativa dos videogames como sendo "procedimental". Esse mesmo conceito, aliás, é utilizado por Galera para distingui-la da narrativa literária em seu ensaio de 2010 sobre os jogos de computador (assim como o pequeno Passage, jogo de cinco minutos que é exemplo frequente quando o autor fala sobre o assunto em entrevistas, aparece claramente no romance por meio do filme de Buster Keaton cujas cenas finais Aurora relembra para si sentada ao lado do pai, transgredindo mais uma vez a fronteira entre autor e narrador). ${ }^{5}$

${ }^{4} \mathrm{Se}$ as referências ao universo pop parecem mais contidas em Meia-noite e vinte, por outro lado chegam quase a chocar as longas intervenções didáticas sobre os animais fabulosos e sobre o Marquês de Sade. Não temos como não pensar, nesses casos, em concessões a um tipo de literatura mais próxima da chamada "literatura de massa", parente do folhetim, "que sempre procurou informar [demonstração de tese], caucionando os acontecimentos imaginários narrados com a divulgação de ideias em curso, doutrinas, fatos jornalísticos, descobertas científicas etc." (Sodré: 1978, 83).

${ }^{5}$ Há mais elementos que vão sendo retomados, como a melancia: Emiliano primeiro diz a Aurora que Duque estaria plantando no sítio (p. 137) e mais tarde ele toma um "suco de melancia" numa lanchonete (p. 165); o "tendão" do tornozelo que Aurora checa para ver se não tinha arrebentado na queda (p. 8), que volta nos "tendões" de Antero no "meuvideo.mp4" (p. 67); a descrição da paixão "número quarenta e cinco" de Os 120 dias de Sodoma [“"Caga na presença de quatro mulheres"” (p. 82)], por Antero, na referência ao filme 2 girls 1 cup (p. 64); os "thumbnails de vídeos pornográficos retirados de websites" mostrados por Antero em sua palestra (p. 84) e os thumbnails sobre os quais ele mesmo mantém o cursor "para exibir o preview de cenas em miniatura" (p. 103), na preparação de sua sessão masturbatória; o "lodo", 
Também o episódio metaficcional que discute o realismo a partir do trabalho da mãe de Aurora, que enquadrou o anúncio de revista transgressor (assim como, no final do mesmo capítulo, Aurora pensa ser uma "transgressão" sentir o cheiro azedo e perfumado de seu pai convalescente) que continha uma cicatriz de cesariana - e os nomes dos personagens nunca são gratuitos nesse livro, como o André, primeiro amor correspondido de Emiliano, dois anos depois do fora que levara de Andrei (etimologicamente "masculino", "viril”) ${ }^{6}$, se parece encerrar uma profissão de fé em favor do realismo, pertence na verdade a uma reflexão não sobre a literatura, mas sobre a publicidade, o mesmo território em que navega Antero, sendo também o curso universitário de formação de Galera.

\section{Gêneros}

Ainda no sentido de destacar as amarrações do texto, lançaremos aqui duas hipóteses para discussão futura: primeiramente, quando, encantada com o livro de Criptozoologia, a jovem Aurora decide seu primeiro "objetivo concreto" na vida: "encontrar

que é o da inconsciência em que cai o filho de Antero após este cantarolar sua "versão música de ninar dos sucessos de Claudinho e Buchecha" (p. 90) e o "lodo no fundo do rio" que Emiliano reluta em revirar, para fazer a biografia de Duque (p. 158).

${ }^{6}$ Semelhantemente, Cunha $(2011,459-60)$, além de proceder à análise dos nomes próprios de Cordilheira, nota, em Mãos de cavalo, a ressonância do nome de Naiara, a "adolescente que se entregara a ele [o jovem Hermano] e com quem [ele] não conseguira realizar qualquer conexão amorosa ou sexual", e que foi "idealizada" por toda a sua vida (pp. 451-2), com o nome da filha do Hermano adulto: Nara. Em Meia-noite e vinte os casos são ainda mais evidentes, como "Duque", o líder do grupo (e que dizer da famosa capa da revista Superinteressante lembrada por Aurora, com "hipercondutores" e "dinossauros"?), e "Aurora", que representa as primeiras manifestações de qualquer coisa (Houaiss), o que assume muita importância para o entendimento do final da estória. 
o veado branco do pampa", que faz parte da "aura enigmática da fauna ainda a descobrir" (Galera: 2016, 27), e o romance, como se sabe, termina realizando esse desejo, com Aurora se deparando finalmente com o tal bicho raro no sítio dos pais de Emiliano. Isso contribui para a sensação, por parte do leitor, de que o ciclo de dúvidas e ansiedade (palavra repetida várias vezes no livro) terminara mesmo, e o que ela tem agora pela frente, que já havia começado inclusive antes do inverno de 2014, é a experiência de "uma liberdade de um tipo que eu nem suspeitava existir" (p. 19), ${ }^{7}$ o mesmo sentimento, aliás, que tem Emiliano após beijar a ex-namorada de Duque.

Pouco antes de decidir passar alguns dias sozinha no sítio, o que lhe possibilita o encontro com o animal, Aurora havia postado no facebook a carta para Duque, fazendo de conta que ele estava vivo, escondido em algum lugar e acompanhando a repercussão da notícia de sua morte. Emiliano telefonou então imediatamente para ela, preocupado mas entrando na brincadeira e contando que Duque estava mesmo no sítio da virada do milênio, e teria pedido que a informação fosse mantida em segredo absoluto. Nossa suposição, tomando como dados a construção engenhosa da trama e a informação passada por Emiliano, é que, ao fazer Aurora encontrar de fato o veado branco do pampa, logo após a descoberta de Emiliano sobre a atração que Dukelsky nutria em segredo por si, o romance estabelece uma relação entre o "veado branco do pampa" e o próprio

${ }^{7}$ É inacreditável que jornalistas tenham feito resenhas do livro aparentemente sem haver lido seu último capítulo. É o que leva a pensar a de Pichonelli, publicada em 2016: “Aurora, uma das personagens de Daniel Galera, não anuncia a manhã, mas um mundo pós-2013 que parece estar "morrendo para sempre", 
Andrei Dukelsky, pois, além de ambos serem ditos igualmente "enigmas" e "mistérios" (pp. 12 e 28), o calão "veado" é utilizado exatamente por Emiliano, e por três vezes (pp. 73, 169 e 171), com o sentido de homem gay. E mais uma quarta quando Antero se apropria de vários cigarros de Emiliano, que o chama então mentalmente de "veadinho" (p. 49). ${ }^{8}$ Para melhor compreender o alcance de tal conexão, localizemos Meia-noite e vinte no fluxo de alguns dos textos de Galera que desenvolvem temas relacionados a gênero. Sabe-se que o autor chegou a ser reconhecido por sua dicção masculina nos dois primeiros livros, ${ }^{9} \mathrm{e}$, quando afinou a voz em Mãos de cavalo, considerado então seu passaporte definitivo como expoente do campo literário brasileiro, estranhamente abriu mão dela logo a seguir para criar uma protagonista mulher em Cordilheira. Segundo nossa interpretação, essa mudança no terceiro romance, além de talvez refletir algum desconforto com a possibilidade de aderência dos protagonistas de seus livros à chamada

8 O veado do pampa ser "branco" pode remeter à cor da camiseta que Duque vestia quando teve sua única experiência homossexual com Emiliano, que destoava, inclusive, das roupas usadas pelos outros frequentadores da festa no Ocidente, camiseta que ele põe também, "toda amassada e meio enfiada na calça jeans" (p. 75), no dia seguinte de manhã, após ter afirmado que não era gay.

${ }^{9}$ Mas também em Barba ensopada de sangue, conforme Vigna (2012) aponta a partir do "único momento do livro em que a homossexualidade é referida" (ainda mais pelo autor ter optado por escrever "homossexualismo", "com seu sufixo denotador de anormalidade", segundo a escritora), deixando, além disso, "gays e mulheres mantidos à distância". Por outro lado, Anna Carolina Botelho Takeda mostra como, em Mãos de cavalo, há "a representação da ruína do modelo de masculinidade em que a virilidade é o elemento determinante", revelando o "sofrimento do garoto [Hermano] diante da impossibilidade de atingir o seu ideal de masculinidade" "gerado pelos discursos produzidos nas narrativas de entretenimento da indústria cultural que sustentam a sua formação cultural” $(2016,163)$. 
"vida real" (cf. "Superando a autoficção" ${ }^{10}$ ), pode ter sido movida também pelo desejo de comprovar sua versatilidade como escritor e eventualmente atender às exigências dos leitores, finalmente introduzindo personagens gays no último romance (ver trecho de entrevista do autor e comentário em Azevedo: 2015, 244).

No entanto, para mostrar que a questão não é tão simples, Carvalho (2002), com acuidade, havia já percebido o bom trânsito de Galera desde o primeiro livro, os contos de Dentes guardados, na elogiosa resenha que fez para a Folha de S. Paulo, ressaltando que, especialmente no conto "Triângulo", o autor "ironiza por tabela o clichê da escrita de macho, aquela que se pretende mais autêntica por ser feita de suor e sangue" - o que, por si só, já retiraria Galera do grupo de escritores visado pela crítica de Bernardo Carvalho com que

\footnotetext{
${ }^{10}$ A rejeição ao conceito de "autoficção", além do esforço emblemático de Clara Averbuck para dissociar-se de sua personagem Camila, é enfatizada também, por exemplo, por Ricardo Lísias (“Eu sou normal”, 2015), cujo personagem Ricardo Lísias, de Divórcio, aliás, torna-se adepto de corridas como o Dukelsky de Galera. Ainda no terreno das coincidências fortuitas, é André o personagem de $O$ céu dos suicidas, cuja morte, ocorrida também antes do início da narração, desencadeia o romance. E tanto Lísias, "quando a própria assinatura, como marca de um nome de autor, ainda se consolidava”, com O livro dos mandarins, investiu repentinamente em uma "contra-assinatura" no que Azevedo, a partir de Beatriz Sarlo, denominou de "guinada subjetiva" em sua carreira (2013, 90-1); como Galera, após ter elaborado "uma assinatura", ter encontrado uma "voz própria" em Mãos de cavalo, muda "uma dicção que mal acaba de se mostrar" (Azevedo: 2015, 244) ao publicar Cordilheira, embora retorne, nas palavras do autor, "com força total ao que seria minha própria voz" (Galera apud Azevedo: 2015, 244), com Barba ensopada de sangue.

A propósito, cremos que até mesmo A vista particular (2016) pode ser lido como mais um jogo autoficcional de Ricardo Lísias, ainda que não tão explícito quanto nos romances de sua autoria em que o protagonista possui o mesmo nome do escritor: ao tirar a roupa e descer dançando em direção à praia, o artista plástico Arariboia encena o percurso literário do próprio autor, que se desnudara em Divórcio e depois experimentaria projetos ousados no cruzamento da literatura com a arte performática.
} 
começamos este texto. Seguindo essa linha de raciocínio, o ardil do desfecho da história de Emiliano e principalmente a surpreendente revelação final sobre Duque, ao fazerem notar detalhes e pistas que na primeira leitura devem ter passado despercebidos a muitos, conferem ao romance uma engenhosidade que, em retrospecto, assemelha-o inesperadamente às novelas de detetive - ramo dos best-sellers, mas, no caso específico, oposto ao realismo tal como definido acima, em virtude de toda sua potência derivar exatamente da exibição das marcas de sua ficcionalidade.

\section{O título}

A segunda hipótese a que gostaríamos de submeter a análise é a sugestão de um entendimento possível para o título do livro. De um lado, ao escrever os numerais por extenso, percebe-se uma mudança em relação a Mãos de cavalo, no qual os capítulos que narram o passeio de carro do Hermano adulto, prestes a enfrentar e vencer o trauma que carrega desde a adolescência, possuem títulos que são todos apenas os horários em que o presente da rememoração vai acontecendo, compreendido entre "6h08" e "8h04". ${ }^{11}$ Pode ser que essa modificação tenha sido necessária para não deixar evidente demais, à primeira vista, a ligação efetuada abaixo.

Pensamos que o horário específico do título do romance foi escolhido pelo fato de ele ser anagrama de "2000", se escrito na

${ }^{11}$ Em Meia-noite e vinte, em menos de duas páginas (pp. 166-7), chama a atenção a quantidade repentina de numerais: "dois papeis", "dois documentos", “dois meses", "dezoito anos", "catorze [anos]", "quinze anos", "dois mil reais", "oito mil [reais]", "dois mil [reais]", "doze parcelas", "meio-dia", "ônibus T9”, "uma e quinze", "trinta reais", "quarenta minutos". Mas isso provavelmente não quer dizer nada. 
forma digital: o ano seguinte ao ápice da vida dos personagens, já então todos em descenso - "e logo depois caíram as torres gêmeas" (p. 92) -, aquele em que não houve o bug do milênio, frustrando as expectativas catastróficas de muitos (e lembremos que, embora Francine tenha tentado engatar em 2012 um estudo antropológico em uma comunidade que havia se preparado para o fim do mundo, é Duque quem, em 2014, ainda reunia material apocalíptico para servir de base a seu próximo livro).

Trocando em miúdos: Antero, Aurora e Emiliano, cada um à sua maneira, caminharam, transitaram de 2000 a 00:20; Duque, por outro lado, o líder do grupo, ídolo dos Orangotangos, sofria com os pés-de-barro que ocultava, e sua vida de suicida virtual, que não havia andado, foi interrompida por causa de um telefone celular, que estava conectado a um aplicativo de corridas. Duque teria ficado preso em 2000, e "meia-noite e vinte" foi a forma que Galera encontrou para falar de sua geração hoje, aquela que, curada a ressaca da primeira madureza, tem de sobreviver no mundo real pós-desbunde. Nas palavras de Averbuck, treze anos depois da Camila de Máquina de pinball:

É tanta vergonha que não cabe em mim, tanta vergonha que não sei se consigo escrever sobre isso. Caberia perfeitamente na personagem, mas seria demais sobre mim. Me exponho até certo ponto, mas assim não sei se consigo. Posso tentar (2015, s/p).

Escrever à meia-noite e vinte é fazer jus a tantas entranhas expostas lá em dois mil e mostrar que Duque está nu, mas no comando: foi ele quem anunciou, "de repente, para a surpresa dos outros, que já era meia-noite e vinte" (Galera: 2016, 199). 


\section{"Autoficção", ainda?}

Escrever à meia-noite e vinte é perguntar onde está a autoficção. Trago o conceito na presunção de que, no caso específico desse romance de Galera, mais que para seus livros anteriores, ele é essencial para a valorização da obra, e não para apontar demérito, como por vezes tem acontecido, resultando na reclamação de alguns autores.

Devido ao engenho com que "baralha a correspondência entre o vivido e o inventado, confundindo o enredo com informações biográficas como uma estratégia capaz de assegurar ao narrador assumir uma pluralidade de vozes" (Azevedo: 2007, 142), produzindo assim o "gesto performático que imbrica a noção de autor, de narrador e as inúmeras vozes-personagens-tipos das narrativas" (Azevedo: 2007, 137), serve o conceito inclusive para afastar de vez qualquer leitura que o filie a uma pretensão de naturalismo, tal como a criticada por Bernardo Carvalho no início deste artigo. O próprio Duque costumava aproveitar suas experiências vividas para fazer delas ficção, como quando foi com Aurora "ver o sol nascer no oceano" depois de uma festa, e ela mesma diz que "sabia que aquela aurora [sic] à beira-mar se tornaria uma cena num de seus livros, o que de fato aconteceu" (Galera: 2016, 133-4). ${ }^{12}$

Partimos, então, de uma resenha jornalística promocional da época de lançamento do romance, na qual Brasil (2016) superfi-

12 “O 'efeito de real' da autoficção, diferentemente do relato realista, não busca aumentar a verossimilhança interna da ficção, mas, 'pelo contrário, quebra com a ficcionalidade e aponta para um além da ficção’ (Klinger: 2007, 45). Autor e narrador - categorias pertencentes, respectivamente, ao fora e ao dentro do texto - se confundem e se excluem simultaneamente, pois, se há elementos que as aproximam e identificam, os textos também exibem suas contrapistas, impedindo o leitor de configurar uma ilusão autobiográfica" (Viegas: 2008, 9). 
cialmente apontou: "os três [Aurora, Antero e Emiliano], de alguma forma, se renderam ao sistema [...]. [E]ntre todos, Duque parecia ser o único a ter resistido em seus ideais [literários], o que o aproxima do próprio Daniel Galera”. Portanto, não chegamos a discordar totalmente da conclusão do jornalista: talvez haja em Duque alguma projeção de Galera, embora não seja possível sabermos, pois essa indefinição é que dá a graça das autoficções. No entanto, Meia-noite e vinte não é um romance polifônico, no sentido bakhtiniano. Apesar de possuir três narradores, não há polifonia, pois por trás deles há uma voz narrativa unívoca, já conquistada em definitivo por seu autor: o narrador do livro, que manipula da primeira à última palavra do texto, é que é Daniel Galera, autor e narrador-regente.

Evidentemente que, guardadas as proporções e mesmo utilizando a expressão não exatamente em seu sentido original, o conceito de "narrador-regente" é caro para Meia-noite e vinte, pois é por meio dele que pode existir a aproximação, de fato, entre Daniel e Andrei. Retiro-o de um artigo sobre Crônica da casa assassinada. Nele, a autora do artigo argumenta, à revelia de boa parte da crítica sobre o romance de Lúcio Cardoso, que o leu como exemplo de polifonia, que, como "o regente de um coral", "há a tentativa de fazer parecer que quem conduz o enredo é ele", esse narrador-regente "que, enquanto compilador dos relatos, define a [des]ordem de como a história é contada, apesar das estratégias particulares de cada narrador-personagem" (Cardoso: 2013, 110).

Em Meia-noite e vinte, claramente não há distinção de estilo entre as falas dos três narradores e, aparentemente, nem de visão de mundo, porque todos são muito parecidos, mesmo dados o idealismo de Aurora, o cinismo de Antero e as dúvidas de Emiliano. No entanto, Galera não repete a estratégia de Cristovão Tezza em O filho eterno, 
que cita os títulos de seus livros ipsis litteris: os títulos de Duque (Morro do Osso, As tardes de excesso e Avatares, além da edição independente de Duas histórias longas e uma curta) não guardam relação com os efetivamente publicados por Galera, mas seu sucesso editorial - "Morro do Osso vendeu sessenta mil [exemplares]" (Galera: 2016, 57) -, os "contratos estrangeiros pros seus três romances" (p. 38) e o fato de que todos seus romances "vão ter versão para o cinema" (p. 58) podem permitir a aproximação dos fictícios aos reais.

Ao seguir tal leitura, Duque é o protagonista único, e não os três narradores. É ele quem, o tempo todo, comanda a narração. O livro foi escrito por Duque, por Galera. Assim, o sentido do título do livro precisa ser revisto, pois não se trata mais somente de um romance de superação, em que os três personagens contariam a posteriori crises pessoais cujos ápice e reviravolta foram propiciados pelo assassinato do amigo em 2014. Se à primeira vista trata-se de um fracasso - pois Duque morreu antes de se realizar integralmente -, foi o viril Andrei, o versátil Daniel com sua voz já inconfundível, que nos enganou o tempo todo, travestido de gay, de macho do fio-terra, de mulher. Duque está lá, sim. No sítio, é o veado branco do pampa, assumido, cuja testemunha é exatamente Aurora.

Pois estamos já em meia-noite e vinte. É somente um livro de ficção.

- Feliz ano novo, Miriguela!

- Opa! Feliz 2005, Brecão.

- Dois mil e quanto?

- Caralho, depois de 2002 perdi a conta.

- Acho que é 2012

(Mirisola: 2014, 85). 


\section{Referências}

AGUIAR, Cristhiano Motta. Ontem, hoje e os outros: ficção brasileira contemporânea e tempo presente. Dissertação de mestrado. Programa de Pós-Graduação em Letras: Teoria da Literatura. Universidade Federal de Pernambuco (UFPE). Recife, 2010.

ASSIS, Laura. "A essencialidade dos 'detalhes inúteis': estratégias de representação em dois romances de Daniel Galera". Brasiliana - Journal for Brazilian Studies, v. 3, nº 1, jul. 2014, pp. 120 38. Disponível em: http://ojs.statsbiblioteket.dk/index.php/ bras/article/view/16734. Acesso em 28 de junho de 2017. AVERBUCK, Clara. Máquina de pinball. São Paulo: Conrad, 2002. . Toureando o Diabo. Ilustrações de Eva Uviedo. São Paulo: Clara Averbuck Lincoln, 2015.

AZEVEDO, Luciene. "Autoria e performance". Revista de Letras, São Paulo, nº 47, pp. 133-58, jul./dez. 2007.

. "Ricardo Lísias: versões de autor". In: CHIARELLI, Stefania; DEALTRY, Giovanna \& VIDAL, Paloma (orgs.). O futuro pelo retrovisor: inquietudes da literatura brasileira contemporânea. Rio de Janeiro: Rocco, 2013, pp. 83-109.

. "Daniel Galera. Profissão: escritor". In: DALCASTAGNE, Regina \& AZEVEDO, Luciene (orgs.). Espaços possiveis na literatura brasileira contemporânea. Porto Alegre: Zouk, 2015, pp. 235-63.

BRASIL, Ubiratan. "Em Meia-noite e vinte, Daniel Galera traça o precioso perfil de personagens nada convictos - Novo livro do escritor faz um retrato de uma geração frustrada". $O$ Estado de S. Paulo. Disponível em: http://cultura.estadao. com.br/noticias/literatura,em-meia-noite-e-vinte-daniel- 
galera-traca-o-precioso-perfil-de-personagens-nada-convictos,10000096503. Acesso em 28 de junho de 2017.

BRITO, Luciano. "O retorno à natureza na ficção brasileira do começo do século XXI". Brasiliana - Journal for Brazilian Studies, v. 3, $\mathrm{n}^{\mathrm{0}}$ 1, jul. 2014, pp. 335-56.

CAMPOS, Simone. A vez de morrer. São Paulo: Companhia das Letras, 2014.

CARDOSO, Elizabeth. "Personagem feminina e múltiplas vozes em Crônica da casa assassinada". O Eixo e a Roda, v. 22, n 1 , 2013, pp. 109-31.

CARVALHO, Bernardo. "Autonomia de um conto". Folha de S. Paulo. Disponível em: http://www1.folha.uol.com.br/fsp/ilustrad/ fq0501200216.htm. Acesso em 28 de junho de 2017.

- "Minha cegueira". Literatura e Sociedade, no 8, 2005, pp. 217-9. Disponível em: http://www.revistas.usp.br/ls/article/ view/19623/21687. Acesso em 28 de junho de 2017.

COMPAGNON, Antoine. O demônio da teoria: literatura e senso comum. Tradução de Cleonice Paes Barreto Mourão e Consuelo Fortes Santiago. Belo Horizonte: Editora UFMG, 2003.

CUNHA, João Manuel dos Santos. "A narrativa de Daniel Galera: mídias confundidas e relações intertextuais”. Raído, v. 5, n ${ }^{0}$ 10, jul.-dez. 2011, pp. 441-66.

ESSINGER, Silvio. "Em Meia-noite e vinte, Daniel Galera fala dos bugs de dois milênios". O Globo. Disponível em: http://oglobo. globo.com/cultura/em-meia-noite-vinte-daniel-galera-fala-dos-bugs-de-dois-milenios-20125821. Acesso em 29 de junho de 2017.

GALERA, Daniel. "Extrair sentidos do tumulto". Entrevista concedida a Camila Von Holdefer. Disponível em: http://www. 
camilavonholdefer.com.br/extrair-sentidos-do-tumulto-uma-entrevista-com-daniel-galera/. Acesso em 29 de junho de 2017.

. “Triângulo". In: . Dentes guardados. Porto Alegre: Livros do Mal, 2004, pp. 32-40.

. "Virando o jogo". Serrote, n ${ }^{\circ} 4$, mar. 2010. Disponível em: http://www.revistaserrote.com.br/2011/06/virando-o-jogo/. Acesso em 29 de junho de 2017.

. Meia-noite e vinte. São Paulo: Companhia das Letras, 2016. . "Superando a autoficção". O Globo. Disponível em: http:// oglobo.globo.com/cultura/superando-autoficcao-7410285. Acesso em 29 de junho de 2017.

JAGUARIBE, Beatriz. "Modernidade cultural e estéticas do realismo". In: O choque do real: estética, mídia e cultura. Rio de Janeiro: Rocco, 2007, pp. 15-41.

KLINGER, Diana. Escritas de si, escritas do outro: o retorno do autor e a virada etnográfica. Rio de Janeiro: 7Letras, 2007.

LÍSIAS, Ricardo. "Eu sou normal”. Scriptorium, v. 1, nº 1, jul.-dez. 2015, pp. 84-100. . A vista particular. Rio de Janeiro: Objetiva, 2016.

MIRISOLA, Marcelo. Hosana na sarjeta. São Paulo: Editora 34, 2014. PICHONELLI, Matheus. "Meia-noite e vinte e ocaso de uma geração". Carta Capital. Disponível em: https://www.cartacapital.com. $\mathrm{br} /$ cultura/meia-noite-e-vinte-e-ocaso-de-uma-geracao. Acesso em 29 de junho de 2017.

RESENDE, Beatriz. Contemporâneos: expressões da literatura brasileira no século XXI. Rio de Janeiro: Casa da Palavra, 2008.

REUTER, Yves. A análise da narrativa: o texto, a ficção e a narração. Tradução de Mário Pontes. Rio de Janeiro: DIFEL, 2002. 
ROHRER, Jason. Passage. Videogame. Disponível em: http://hcsoftware.sourceforge.net/passage/.

SODRÉ, Muniz. Teoria da literatura de massa. Rio de Janeiro: Tempo Brasileiro, 1978.

TAKEDA, Anna Carolina Botelho. "A obsessão pela virilidade em Mãos de cavalo: poder e ruína". Revista Estação Literária, v. 16, jun. 2016, pp. 153-64.

VIEGAS, Ana Cláudia. “O 'eu' como matéria de ficção - o espaço biográfico contemporâneo e as tecnologias digitais". Revista Texto Digital, n 2, 2008, pp. 2-13.

VIGNA, Elvira. "Barbas pouco confiáveis”. Disponível em: etudeslusophonesparis4.blogspot.com.br/2012/11/barbas-pouco-confiaveis.html. Acesso em 29 de junho de 2017. 


\section{Resumo}

O ensaio empreende uma leitura do romance Meia-noite e vinte (Galera, 2016) que ressalta inicialmente a engenhosidade de sua construção, perseguindo correlações de episódios do enredo aparentemente desconectados entre si. Exemplificada a astúcia da composição, levantamos uma hipótese interpretativa para o desfecho da estória, identificando, no veado branco do pampa encontrado por Aurora no último capítulo, uma referência ao personagem Andrei Dukelsky, o que afastaria de vez os rótulos de "pessimista" e "niilista" imputados ao livro por parte da crítica; e uma hipótese para a compreensão do título como anagrama de "2000", o que possibilitaria entender a obra como reflexão metaficcional do autor sobre sua década e meia de trajetória literária. Por fim, concluímos que, em vez de polifônico, é na verdade Duque, por encarnar a já peculiar voz autoral de Galera, quem conduz, como "narrador-regente", toda a narração. Assim, o romance se enriquece se lido na chave da autoficção.

\section{Palavras-chave: Daniel Galera; Meia-noite e vinte; autoficção.}

\section{Abstract}

This essay undertakes a reading of the novel Meia-noite e vinte (Galera, 2016) that initially emphasizes the inventiveness of its construction, pursuing correlations of apparently disconnected plot episodes. Exemplified the craftiness of the composition, we raised an interpretative hypothesis for the ending of the story, identifying, in the white deer of the pampa found by Aurora in the last chapter, a reference to the character Andrei Dukelsky, which would remove the labels of "pessimist" and "nihilist" imputed to the book by the critics; and a hypothesis for the understanding of the title as anagram of "2000", which would make it possible to understand the work as a metafictional reflection by the author on his decade and a half of literary trajectory. Finally, we conclude that, rather than polyphonic, it is Duque who, in fact, by embodying Galera's already peculiar authorial voice, conducts the whole narrative as "narrator-regent", and the novel will thus be enriched if read in the key of autofiction.

Keywords: Daniel Galera; Meia-noite e vinte; autofiction. 